\title{
Use of statistical indicators of profit accounting for formation of a product portfolio
}

\author{
L.G. Nesterova ${ }^{1, *}$ \\ ${ }^{1}$ South Ural State University, Chelyabinsk, Russia
}

\begin{abstract}
Article is related to perfection of product portfolio policy of the enterprise by formation of a product portfolio by means of using of statistics methods and mathematical criteria of the games theory. Such approach allows to decide many tasks of marketing at the enterprise, including to use results of marketing researches and demand and profit forecasting. As a result of the offered system of calculations of statistical indicators it is possible to receive a matrix of predicted risks and market growth for a concrete product portfolio, and also to estimate potential and market prospects of concrete commodity groups. It will form an optimal product portfolio for the specific market conditions.
\end{abstract}

\section{Introduction}

Planning of development of a product portfolio always is an actual task of product portfolio policy of any enterprise. There are various approaches for definition of strategy of such development. This article offers to consider the approach with use of a combination of statistical techniques of the accounting profit and two mathematical criteria of the games theory.

The offered approach of a choice of development strategies of the product portfolio which initial element is the set of possible values of profit, synthesizes into itself elements of several stages of marketing management. As marketing tasks [1-7] within the limits of use of our approach the following can be offered:

- Increase of efficiency of company activity;

- Increase of company stability (decrease of activity risks) in the conditions of uncertainty of market.

As the marketing purposes [1-7] with reference to formation and development of a product portfolio can be following:

- Diversification of company activity;

- Statement of planning system and forecasting in the conditions of variability of market;

- Statement of system of marketing audit (control of development efficiency of existing economic units).

Marketing research [4-6, 8-11] within the limits of our approach has double character:

- It is one of situation analysis methods (really, we define more exact distribution of possible market situations);

- One of controlling methods (we subject to control aprioristic estimations of possible conditions of market).

- Marketing research [4-6, 8-11] executes two functions:

- Definition of possible conditions of market conditions (including, allocation of the data due to strategic segments), that is transition from a condition of full uncertainty to the partial condition; marketing research the situation analysis tool;

- Correction of already existing expert estimations toward a market situation; marketing research - the tool of control of marketing.

\section{Use of statistical indicators of profit accounting for formation of a product portfolio}

\section{A. Matrix of predicted risks and market growth}

Such approach allows to present prospects of a product portfolio within the limits of model General Electric/McKinsey [1-3, 5, 12, 13]. Really, we can obtain the estimated data about predicted rates of increase of the markets of strategic units, as well as to calculate relative predicted risk of investment. For each of the given indicators we can break the markets, the goods, SEU (STRATEGIC ECONOMIC UNIT) into three groups:

- Within the limits of predicted rate of increase:

- Fast growth (more than set top bound of stability criterion);

- Relative stability (within the limits of bounds of stability criterion);

- Falling (less than the lower bound of set stability criterion);

- Within the limits of relative investments risk:

- High risk;

- Average risk;

- Low risk.

Under criterion of stability are understood such bounds of increase rates which are estimated by the person, making the decision, as normal (averages) for the considered market as a whole. As a result of breaking the following matrix to which we recommend to apply

Corresponding author: nesterovalg@susu.ru 
strategies of adaptive growth [1, 7, 12, 14-16]. Name the received model as a matrix of predicted risks and market growth (table I).

Table 1. Matrix of predicted risks and market growth.

\begin{tabular}{|c|c|c|c|c|}
\hline & & \multicolumn{3}{|c|}{ Relative predicted growth } \\
\hline & & $\begin{array}{c}\text { Fast } \\
\text { growth }\end{array}$ & Stability & Falling \\
\hline \multirow{3}{*}{ 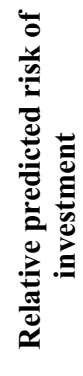 } & Low & Approach & Approach & Deduction \\
\hline & Average & Approach & Deduction & Deviation \\
\hline & High & Deduction & Deviation & Deviation \\
\hline
\end{tabular}

\section{B. Use of statistical indicators}

Use of criterion of Laplace [17-19]

$$
L=\max _{i}\left(\frac{1}{n} * \sum_{k=1}^{n} P F i k\right)
$$

The criterion shows the maximum value of a mathematical expectation of profit receipts for various strategic units. The criterion bases on the precondition that all values of a consumer demand are equiprobable.

Within the limits of our model the person making decision, will receive total ranged in places a row of strategic units according to decrease of row of average values of expected profit. Present row will specify to average values of profit expected by company (caused due to averaged among expected conjuncture) for each of reviewed groups. Actually in the top part of a row (with the highest places) the goods with the greatest average expected potential of release will be located. Name the present row as a row of Laplace.

Finding method:

Originally for each strategic unit we find the size of total profits under all possible conditions of market. Then we choose the strategy which provides to the businessman the maximum possible receipts of profit.

Use of criterion of Bayes-Laplace [17; 18; 19] (for an estimation of efficiency of marketing research)

$$
B L=\max _{i}\left(\sum_{k=1}^{n}\left(P F_{i k}^{*} p\left(D P_{k}\right)\right)\right)
$$

This criterion shows the maximum value of a mathematical expectation of profit receipts under various strategies of company taking into account the data about the demand levels received on the basis of some (on the basis of marketing research) expert distribution of probabilities of consumer potential values - $\mathrm{p}(\mathrm{DPk})$.

Within the limits of our model the person making decision will receive total ranged in places a row of strategic units according to decrease of the weightedaverage of expected profit receipts. This row will specify to weighted taking into account the probabilities expected by company, values of profit (due to weighted likelihood average among expected by a conjuncture) for each of considered groups. Actually in the top part of a row (with the least places) the goods with the greatest average probable potential of release will be located. Name the present row as a row of Bayes-Laplace.

Finding method:

At the first stage the businessman sets values of distribution probabilities of possible demand levels (for example, on the basis of the previous experience, or after carrying out of the predicted analysis of the market development). Then, taking into account likelihood conditions a demand determinant, for each strategic unit we find the size of total profit receipts. And, at last, we choose the strategy which provides to the businessman the maximum possible receipts of profit. It will be optimum by the given criterion.

For each strategy of product portfolio development it is possible to present set of profit values in a kind ranged a variation row. It allows us to calculate for each strategy average value of profit, and taking into account distribution of probabilities of market conditions and the weighted-average, as well as an average quadratic deviation and variation factor. Notice that the set of average and weighted-average represents rows of Laplace and Bayes-Laplace accordingly.

Let's designate average value of profit receipts under strategy $\mathbf{i}$ as AGRi (average gross receipt average receipt of profit), and probable-average (weighted) receipt of profit as APGRi (average probable gross receipt - average probable receipt of profit). Profit receipts under strategic unit $\mathbf{i}$ at a conjuncture $\mathbf{k}$ are designated as PFik.

Average quadratic deviation (AQD) we will count under following formulas [17-20]:

For a row of Laplace

$$
\sigma_{i}=\sqrt{\frac{\sum_{k=1}^{n}\left(P F_{i k}-A G R_{i}\right)^{2}}{n}}
$$

For a row of Bayes-Laplace

$$
\sigma_{B L_{i}}=\sqrt{\sum_{k=1}^{n}\left(p\left(D P_{k}\right) *\left(P F_{i k}-A P G R_{i}\right)^{2}\right)}
$$

Variation factor we will count under formulas [1720]:

For a row of Laplace

$$
v_{i}=\frac{\sigma_{i}}{A G R_{i}}
$$


For a row of Bayes-Laplace

$$
v_{B L_{i}}=\frac{\sigma_{B L_{i}}}{A P G R_{i}}
$$

In our approach the variation factor is used for definition of relative risk of investment in an alternative matrix of predicted risks and market growth. For construction of the given matrix it is necessary to divide all goods, SEU (STRATEGIC ECONOMIC UNIT), the markets into three groups due to investment risk levels. For this purpose we suggest to break a row of variation factors into three equal intervals. Length of an interval we will define under the following formula [17-20]:

For a row of Laplace

$$
\Delta v=\frac{\max _{i} v_{i}-\min _{i} v_{i}}{3}
$$

For a row of Bayes-Laplace

$$
\Delta v_{B L}=\frac{\max _{i} v_{B L}-\min _{i} v_{B L}}{3}
$$

Thus, the relative risk of investments for each strategy i can get to one of three groups (an example for a row of Laplace):

High risk $\max v-\Delta v<v_{i} \leq \max v$;

Average risk minv $+\Delta v<v_{i} \leq \max v-\Delta v$;

Low risk $\min v \leq v_{\mathrm{i}} \leq \min v+\Delta v$.

Following indicator which is necessary for construction of a matrix of predicted risks and market growth, is average predicted rate of increase. We will count it as follows [17-20]:

For a row of Laplace

$$
T_{i}=\frac{A G R_{i}-P F_{i 1}}{P F_{i 1}}
$$

For a row of Bayes-Laplace

$$
T_{B L_{i}}=\frac{A G P R_{i}-P F_{i 1}}{P F_{i 1}}
$$

Here PFil - the size have arrived to an initial stage.

Then it is necessary to divide the goods, SEU (STRATEGIC ECONOMIC UNIT), the markets into three groups of growth, for this purpose it is necessary to set criterion of stability. The criterion of stability will characterize the top and lower bounds of rates of increase of the investigated markets which the person making decision considers expedient to define. On the basis of the entered bounds each strategic unit $\mathbf{i}$ will get to one of three groups (an example for a row of Laplace):

Fast growth: $\mathrm{Ti} \geq$ the top bound of stability criterion;

Stability: $\mathrm{Ti}$ lies within bounds of stability criterion;
Falling: $\quad \mathrm{T} i \leq$ the lower bound of stability criterion. Average rate of increase we will define as follows: For a row of Laplace

$$
\bar{T}=\frac{1}{m} * \sum_{i=1}^{m} T_{i}
$$

For a row of Bayes-Laplace

$$
\bar{T}_{B L}=\frac{1}{m} * \sum_{i=1}^{m} T_{B L}
$$

For matrix General Electric/McKinsey it is necessary for us to break all strategic units into three groups according to their potential which is expressed in average profit receipts for a row of Laplace and possible average receipts of profit for a row of Bayes-Laplace. For this purpose we suggest to break a row of necessary average values into three equal intervals. Length of an interval we will define under the following formula [1720]:

For a row of Laplace

$$
\Delta A G R=\frac{\max _{i} A G R_{i}-\min _{i} A G R_{i}}{3}
$$

For a row of Bayes-Laplace

$$
\triangle A P G R=\frac{\max _{i} A P G R_{i}-\min _{i} A P G R_{i}}{3}
$$

Thus, $\mathbf{i}$ within the limits of matrix GE it is possible to define a relative position of: strategic unit as follows (an example for a row of Laplace):

Successful: $\operatorname{maxAGR}-\triangle \mathrm{AGR}<\mathrm{AGRi} \leq \operatorname{maxAGR}$;

Average: $\min A G R+\triangle \mathrm{AGR}<\mathrm{AGRi} \leq$

$$
\leq \operatorname{maxAGR}-\triangle \mathrm{AGR}
$$

Unsuccessful: $\min A G R \leq \mathrm{AGRi} \leq \min \mathrm{AGR}+\Delta \mathrm{AGR}$.

\section{Conclusion}

Table 2. Example of a summary matrix of predicted risks and market growth for commodity categories A,B,C.

\begin{tabular}{|c|c|c|c|c|}
\hline \multicolumn{2}{|c|}{} & \multicolumn{3}{|c|}{ Relative predicted growth } \\
\cline { 3 - 5 } \multicolumn{2}{|c|}{} & $\begin{array}{c}\text { Fast } \\
\text { growth }\end{array}$ & Stability & Falling \\
\hline \multirow{2}{*}{$\begin{array}{c}\text { Relative } \\
\text { risk of } \\
\text { investment }\end{array}$} & Low & A & A & C \\
\cline { 2 - 5 } & Average & A & C & B \\
\cline { 2 - 5 } & High & C & B & B \\
\hline
\end{tabular}

We can formulate the following conclusions:

Use of this approach allows to generate as the general strategy of development of a product portfolio, and to define potential and prospects of its separate units.

This approach will form an optimal product portfolio for the specific market conditions. 
The work was supported by Act 211 Government of the Russian Federation, contract № 02.A03.21.0011.

\section{References}

1. I. Ansoff, Strategic management (Economy, Moscow, 1993)

2. I. Ansoff, New corporate strategy (Piterkom, St. Petersburg, 1999)

3. G. Assel, Marketing: principles and strategy (Infra Th, Moscow, 2003)

4. R.D. Bazzel, D.F. Koks, R.V. Brown, Information and risk in marketing (Finstatinform, Moscow, 2007)

5. F. Kotler, Principles of marketing. Rostinter (Moscow, 2005)

6. J. Traut, New positioning (Peter, St. Petersburg, 2003)

7. D. Etkinson, Strategic marketing: situations, examples: Studies. The grant for high schools (Uniti - Dana, Moscow, 2011)

8. E.O. Putmen, Marketing of your fields of activity (New York, the USA, 1998)

9. A. Hayem, Marketing for teapots (Dialectics, Kiev, 2010)

10. G.A. Churchill, Marketing researches (Peter, St. Petersburg, 2005)
11. R.A. Shmidt, H.A. Right, Financial aspects of marketing: Studies. The grant for high schools of economic specialities (Uniti, Moscow, 2012)

12. A.I. Veselov, Marketing in Russia and abroad, 1, 103-114 (2009)

13. N.U. Chernik, The commodity policy of the enterprise: Studies (Publishing house BGEU, Minsk, 2004)

14. R. Watermen, Faktor of management by results (Progress, Moscow, 1998)

15. R. Watermen, Faktor of updating: how the best companies keeps competitiveness (Progress, Moscow, 2008)

16. R. Foster, Modification of manufacture: the attacking win (Progress, Moscow, 2006)

17. E.S. Pozhidaeva, Statistika: the textbook for high schools (Academy, Moscow, 2015)

18. S.D. Beshelev, F.G. Gurvich, Mathematical statistical methods of expert estimations (Statistics, Moscow, 1995)

19. P.V. Konjuhovsky, A.S. Malov, Theory of games: the textbook for high schools of economic directions and specialities (Urayt, Moscow, 2015)

20. K. Heddervik, Financial and economic analysis of enterprises activity (Finance and statistics, Moscow, 2006) 